\title{
TISSUE SAPROPHYTES AND THE POSSIBILITY OF BIOLOGICAL CONTROL OF SOME TREE DISEASES
}

\author{
By JOHN E. BIER
}

\begin{abstract}
In presenting the results of this research grateful acknowledgment is given to MacMillan, Bloedel and Powell River Limited, and the National Research Council of Canada for the provision of financial grants in support of the studies. Should the results prove of value to Forestry, considerable credit would be due to these agencies for their continued interest and support.
\end{abstract}

It is felt that there is an urgent need in forest research to establish "Clinical Indices" within trees that will enable Foresters to classify the degree of health, vigor, and disease vulnerability in different stands. It is insufficient to relate the incidence or severity of a disease with abstract factors such as soil and climate since the results of such analyses may have limited application and lead to a number of multiple correlations that are difficult to assess or define. At this point a lesson may be learned from the practice of Medicine. Initially the Doctor does not make detailed analyses of the patient's nutrition, nor the atmospheric environment in which he or she may live. First diagnosis consists of clinical tests such as the patient's pulse, blood pressure, etc. The state of health or disease indicated by these tests may lead to the factors of malnutrition, sudden chilling, etc. It is believed that clinical tests, easy to perform, may be taken in trees which will indicate their level of health and susceptibility or resistance to diseases. Furthermore, such clinical tests may establish whether the disease under investigation had developed primarily because of some nutritional or climatic disturbance.

The results of studies (2) on the moisture content of functional, living cells in the young bark and foliage of trees have demonstrated excellent correlations between the moisture content of the cells and the level of tree vigor based upon factors such as rooting potential and vulnerability to a number of canker diseases. Therefore, the moisture level of these tissues may serve as one of many useful "Clinical Indices", that may be discovered in the future. High moisture content in functional cells has indicated healthy and disease resistant tissues that were able to absorb and retain more moisture during periods of stress.

\footnotetext{
${ }^{1}$ Professor, Forest Pathology, University of British Columbia, Vancouver, B.C.
} 
There is a difference in the physiology of trees and man that frequently is not fully appreciated. The physiological processes in a healthy man are similar during all months of the year. Trees, on the other hand, experience two distinctly different periods of physiological activity each year. During growth which may last 3 or 4 months the tree is very active physiologically and capable of preventing infection by the rapid healing of wounds, production of resin, etc. During dormancy which may last 7 or 8 months of the year the tree is inactive and unable to perform many of the phenomena which will assist in preventing disease attack. If we wish to establish which are the most vigorous trees or stands and, therefore, least susceptible to many diseases, perhaps the clinical tests should be made during the dormant period rather than when the trees are in full growth. Certainly, in all tree species investigated the moisture content of the functional cells in bark and foliage has been appreciably less during the dormant period.

During the investigations on bark and leaf moisture ( 3 and 4 ) it became evident that the healthy tissues of trees were colonized by numerous harmless saprophytes (fungi and bacteria). Indeed, healthy foliage and bark should not be considered as entities but rather as complex biological communities. Furthermore, a number of the saprophytes on healthy tissues were proven to be very efficient individually or collectively in preventing infection by different disease-causing organisms. These saprophytes occurred both externally and internally in healthy trees and provided the maximum degree of protection against disease attack when the tissues contained an abundant supply of water. A moisture differential was demonstrated for the optimum development of the saprophytes and pathogens on living trees. When the moisture content of the tree tissues was lowered too far the saprophytes became ineffective in preventing infection.

However, the degree of coverage of forest trees by the saprophytes is accidental, the organisms reaching the tissues by factors such as wind and rain. Some trees or parts of trees (e.g. new growth) may be colonized by fewer saprophytes than others, and contain less than the minimum necessary to provide this type of resistance. Such being the case would it be possible to apply dips or sprays containing large numbers of the saprophytes and achieve a degree of biological control of tree diseases? Furthermore, applying more saprophytes to supplement those provided by Nature may lead to lowering the threshold level of moisture for infection, which would enable the trees to withstand greater drought and adversity and remain free from disease attack.

The results of laboratory experiments ( 3 and 4 ) have shown that solutions containing a sufficient number of saprophytes to control a number of tree diseases may be prepared very easily by placing one gram of healthy leaf or bark tissue into a flask containing 75 c.c. of sterile, distilled water. The flasks are placed on a slow speed shaker for a period of approximately 5 days at room temperature. The leaf or bark tissues provide the nutrition and the shaker the aeration for the growth and multiplication of the saprophytes. Applications of these solutions to inoculated trees in the laboratory have proven effective in controlling the diseases caused by a number of 
bark canker and decay fungi, and one leaf rust fungus. These pathogens are representative of a broad range in types of tree diseases.

Applications of the solutions containing the saprophytes would appear to result in a higher level of tree vigor in addition to preventing infection. Preliminary experiments (5) have indicated that the production of secondary roots was increased appreciably when the basal ends of cuttings were placed in contact with the test solutions. Therefore, the solutions may have served a dual purpose, and were proven not to injure the newly-developing roots and shoots. It is well to remember that the application of toxic chemicals to trees will result in the destruction of the beneficial saprophytes in addition to the disease-causing organisms.

The procedures outlined may prove to be an inexpensive method of supplementing nature to achieve the biological control of some tree diseases. The results of field trials are necessary to assess the value of spray treatments.

The following statement was made in the summary of a paper (1) presented at the Annual Meetings of the C.I.F. in Saskatoon in 1955: "Sound recommendations for prevention or control of tree diseases will not be available until a better knowledge is obtained on the basic factors influencing the host-parasite relationships within a forest." If any value is achieved from this research it will be due to a strict adherence to this principle.

\section{REFERENCES}

1. BIER, J. E. 1955. Protection against tree diseases, For. Chron. 31; 324-331.

2. 1961. The relation of bark moisture to the development of canker disease caused by native, facultative parasites. V. Rooting behavior and disease Vulnerability in cuttings of Populus trichocarpa Torrey and Gray, and P. 'robusta'. Can. J. Botany 39; $145-154$.

3. - and ROWAT, MARIAN H. 1962. The relation of bark moisture to the development of canker diseases caused by native, facultative parasites. VII. Some effects of the saprophytes on the bark of poplar and willow on the incidence of Hypoxlon canker. Can. J. Botany $40 ; 61-69$.

4. - and ROWAT, MARIAN H. 1962. The relation of bark moisture to the development of canker diseases caused by native, facultative parasites. VIII. Ascospore infection of Hypoxylon pruinatum (Klotszsch) Cke. Can. J. Botany 40;897-901.

5. $\longrightarrow$ 1962. Acti-dione and natural bark extracts in the control of Hypoxylon canker of poplar. For. Chron. 38; 363-366. 